\title{
High Speed Ultraviolet Phototransistors based on an Ambipolar Fullerene Derivative
}

\author{
Wentao Huang ${ }^{1}$, Yen-Hung Lin ${ }^{1}$, \& Thomas D. Anthopoulos ${ }^{1,2 *}$ \\ ${ }^{1}$ Centre for Plastic Electronics and Department of Physics, \\ Blackett Laboratory, Imperial College London, \\ London SW7 2BW, \\ United Kingdom \\ ${ }^{2}$ King Abdullah University of Science and Technology (KAUST), \\ Division of Physical Sciences and Engineering, \\ Thuwal 23955-6900, Saudi Arabia \\ *Corresponding to: thomas.anthopoulos@kaust.edu.sa
}

Keywords: PCBM; ambipolar transport; phototransistor; UV photodetector; fullerenes

\begin{abstract}
-
Combining high charge carrier mobility with ambipolar transport in light absorbing organic semiconductors is highly desirable as it leads to enhanced charge photogeneration, and hence improved performance, in various optoelectronic devices including solar cells and photodetectors. Here we report the development of [6,6]-phenyl-C61-butyric acid methyl ester ( $\left.\mathrm{PC}_{61} \mathrm{BM}\right)$-based ultraviolet (UV) phototransistors with balanced electron and hole transport characteristics. The latter is achieved by fine-tuning of the source-drain electrode work function using a self-assembled monolayer. Opto/electrical characterization of as-prepared ambipolar $\mathrm{PC}_{61} \mathrm{BM}$ phototransistors reveals promising photoresponse, particularly in the UVA region $(315-400 \mathrm{~nm})$, with maximum photosensitivity and responsivity of $9 \times 10^{3}$ and $3 \times 10^{3} \mathrm{~A} / \mathrm{W}$ respectively. Lastly, the temporal response of the $\mathrm{PC}_{61} \mathrm{BM}$ phototransistors is found to be high despite the long channel length $(10 \mathrm{~s}$ of $\mu \mathrm{m})$ with typical switching times of $<2 \mathrm{~ms}$.
\end{abstract}




\section{INTRODUCTION}

Organic thin film transistors (OTFTs) have been intensively studied due to their attractive characteristics that include mechanical flexibility and processing versatility that enables costeffective manufacturing on inexpensive substrate materials. ${ }^{1-5}$ Unlike incumbent silicon transistor technologies where p-type and n-type functionality is achieved via implantation of suitable dopants, charge transport in organic semiconductors, and their devices, is determined by the molecular structure and the ability to inject holes and/or electrons in the corresponding energy levels. This property has enabled the development of OTFTs that are able to transport holes and/or electrons, depending on the biasing conditions, within the same channel material. ${ }^{6}$ These so-called ambipolar transistors have shown promise for a range of applications ${ }^{7-10}$ as they combine multiple functions that include electrical switching, light-sensing and light emission. ${ }^{11-15}$ To this end, organic phototransistors (OPTs) represent an important emerging technology as they offer light-sensing capabilities with electrical switching which makes them ideal for use as electro-optical transducer for signal-amplification. Such attractive characteristics are key for overcoming the noise level in conventional photodiode read-out circuit $^{16}$ as the tuneable gain mechanism controlled by the gate field (exclusive to transistor's three-terminal architecture) enables controllable sensitivity and low noise level compared to the conventional two-terminal photodiodes. ${ }^{17}$ Moreover, the structural versatility of organic semiconductors with tailor-made properties allows the design for OPTs with desired functionality such as panchromatic sensitivity or wavelength selectivity. ${ }^{18-22}$

Methanofullerene derivatives such as the [6,6]-phenyl-C61-butyric acid methyl ester $\left(\mathrm{PC}_{61} \mathrm{BM}\right)$, have been extensively used as electron-transporting materials in $\mathrm{n}$-channel OTFTs,${ }^{23-26}$ in combination with p-type semiconductors to form heterostructure ambipolar OTFTs $^{27-29}$ as well as the electron acceptors in organic photovoltaics (OPVs). ${ }^{30-34}$ Although a few early attempts have demonstrated ambipolar transport in $\mathrm{PC}_{61} \mathrm{BM}$ transistors, emphasis 
was placed on circuit applications. ${ }^{7,35}$ This interesting combination of characteristics makes $\mathrm{PC}_{61} \mathrm{BM}$ a promising candidate for applications in the area of photodetectors and particularly phototransistors. Despite the promise, however, to date no ambipolar OPT based on $\mathrm{PC}_{61} \mathrm{BM}$ has been demonstrated.

Herein we report the development of ambipolar $\mathrm{PC}_{61} \mathrm{BM}$ transistors with balanced electron and hole mobilities and their application as fast and highly sensitive UV photodetectors. Resulting devices were electrically characterised in the dark and under illumination with different light intensities and wavelengths. When illuminated with different wavelengths of light the OPTs are found to be visible blind with significant photoresponse observed only under UV illumination. The extracted figures of merit of $\mathrm{PC}_{61} \mathrm{BM}$-based OPTs are shown to be comparable to those reported for state-of-the-art silicon photodetectors. Lastly, the $\mathrm{PC}_{61} \mathrm{BM}$ phototransistors show excellent dynamic response with turn-on and turn-off times of less than $2 \mathrm{~ms}$. The present results highlight the potential of ambipolar $\mathrm{PC}_{61} \mathrm{BM}$ phototransistors as an alternative, and highly promising, UV photodetector technology.

\section{EXPERIMENTAL SECTION}

\subsection{Device Fabrication}

Top-gate, bottom-contact (TG-BC) transistors were fabricated on $2 \mathrm{~cm} \times 2 \mathrm{~cm}$ glass substrates. Prior to material deposition all substrates were cleaned by sonication in detergent solution (DECON90), deionized water, acetone and 2-propanol (IPA) for 10 minutes each. 40-nm-thick gold source and drain (S-D) contacts were thermally evaporated onto the substrates through shadow masks, resulting to transistors with channel length (L) and width (W) of $30 \mu \mathrm{m}$ and 1 $\mathrm{mm}$, respectively. The surfaces of the S-D contacts were then chemically modified with the functionalization of the pentafluorothiophenol (PFBT) self-assembling monolayer by 
immersing the substrates into a 1:100 vol.\% diluted solution of PFBT in IPA for $1 \mathrm{~h}$ at room temperature in air. The excess of PFBT was washed off with IPA. The $\mathrm{PC}_{61} \mathrm{BM}$ layer was then deposited by spin-casting from a chlorobenzene solution $(20 \mathrm{mg} / \mathrm{ml})$ at a spin speed of 1200 rpm for $60 \mathrm{~s}$, followed by a 10 -min annealing at $100{ }^{\circ} \mathrm{C}$ in nitrogen. The fluoropolymer CYTOP (Asahi Glass) was used as the gate dielectric layer and spin-coated directly onto the semiconducting layer at $2000 \mathrm{rpm}$ for $60 \mathrm{~s}$ and dried in high vacuum $\left(\sim 10^{-7}\right.$ bar $)$ for $10 \mathrm{~h}$. Device fabrication was completed with the thermal evaporation of 40-nm Al gate electrode through a shadow mask onto the CYTOP layer.

\subsection{Material Characterization}

Film absorption measurements were performed using a Shimadzu UV2600 UV-Vis spectrophotometer equipped with an ISR-2600 Plus integrating sphere. The samples for the UV-Vis measurement were made on quartz substrates, following an identical recipe of material deposition to that described previously in Section 2.1. The absorption spectrum was calculated from the measured transmittance and reflectance data. The surface morphologies of the various deposited films and the glass substrate, were obtained using an Agilent 5500 atomic force microscope in intermitted contact mode. The work function of the Au electrodes before and after PFBT treatment was determined using a scanning Kelvin Probe (KP) system (KP Technology, SKP5050) using silver (Ag) as the reference workfunction material. The deposition of $\mathrm{Au}$ and the functionalization of the PFBT monolayer were performed using the same procedures to those described in Section 2.1.

\subsection{Optoelectronic Characterization}


Optoelectronic characterization was carried out by measuring the transfer and output characteristics of the fabricated transistors in dark environment and under various illumination intensities using red-green-blue (RGB) and UV light-emitting diodes (LEDs). Specifically, LEDs with electroluminescence (EL) emission peaks at 632, 525, 475 and $390 \mathrm{~nm}$, were employed and driven using a Keithley 2400 source-meter. Electrical characterisation of all transistors was performed using an Agilent B2902A source-measure unit in dry nitrogen atmosphere. The illumination intensities $\left(E_{\text {opt }}\right)$ generated by the LEDs driven at different current levels were measured by a Thorlabs S120UV power sensor.

Three figures of merit were used to assess the response of the OPTs, namely photosensitivity $(P)$, responsivity $(R)$ and specific detectivity $\left(D^{*}\right) . P$ is defined as the ratio of photo-generated current to the dark current and is given as:

$$
P=\frac{I_{p h}}{I_{\text {dark }}}=\frac{I_{\text {illum }}-I_{\text {dark }}}{I_{\text {dark }}}
$$

where, $I_{\mathrm{ph}}$ is the photocurrent, $I_{\mathrm{illum}}$ is the channel current under illumination and $I_{\text {dark }}$ is the drain current in dark. On the other hand, $R$ is defined as the ratio of photo-generated current to the incident optical power $\left(P_{\text {opt }}\right)$. The magnitude of $R$ can be calculated through the following equation:

$$
R=\frac{I_{p h}}{P_{\text {opt }}}=\frac{I_{\text {illum }}-I_{\text {dark }}}{E_{\text {opt }} \cdot a}
$$

where, $a$ is the device area. The value of $D^{*}$ is a figure of merit with respect to the noise and is defined as:

$$
D^{*}=\frac{\sqrt{a} \cdot R}{S_{\text {noise }}}
$$

Here, $S_{\text {noise }}$ the noise spectral density. There are various sources contributing to the total noise that limit $D^{*}$ and include, Johnson noise, thermal fluctuation "flicker" noise and shot noise. 
The shot noise from the dark current is commonly considered to be the major contribution to the total background noise. ${ }^{18,36-39}$ Based on this assumption, the expression for the shot-noise limited detectivity $D_{s}^{*}$ can be written as:

$$
D_{S}^{*}=\frac{\sqrt{a} \cdot R}{\sqrt{2 q I_{\text {dark }}}}
$$

where $q$ is the electron charge.

\subsection{Temporal Response Measurements}

Dynamic characterization was performed by measuring the evolution of the channel current to an external optical stimulus (light pulse). To achieve this, the transistor was biased at fixed drain $\left(V_{\mathrm{D}}\right)$ and gate $\left(V_{\mathrm{G}}\right)$ voltages using an Agilent B2902A source-measurement unit as in electrical characterization and the variation in channel current was amplified by Stanford Research Systems SR570 current preamplifier and subsequently recorded by an Agilent DSO6014A oscilloscope. Optical pulses were generated using different light colour-emitting LEDs driven by an Agilent 33220A function generator.

\section{RUSULTS AND DISCUSSION}

\subsection{Film Characterization}

The absorption spectrum of the $\mathrm{PC}_{61} \mathrm{BM}$ layers deposited on quartz substrates were first investigated using a UV-Vis spectrophotometer (Figure 1a). Evidently, the compound exhibits weak absorption in red region and moderate absorption in green-blue range. The weak absorption at longer wavelengths is attributed to the relatively wide band gap of $\mathrm{PC}_{61} \mathrm{BM}-\mathrm{a}$ result of the peculiar electronic structure of $\mathrm{C}_{60}{ }^{40}$ However, the absorption increases 
significantly in the UV-A region $(<400 \mathrm{~nm})$, hence making $\mathrm{PC}_{61} \mathrm{BM}$ a promising candidate for use in UV photodetectors.

The surface topography of the $\mathrm{PC}_{61} \mathrm{BM}$ layers deposited on glass was investigated using atomic force microscopy (AFM) and is shown in Figure 1b. The surface morphology of the bare glass surface is also shown for comparison. The $\mathrm{PC}_{61} \mathrm{BM}$ layer appears extremely smooth and uniform with a root-mean-square (RMS) roughness of $\sim 0.26 \mathrm{~nm}$, which is close to that of glass beneath $(\sim 0.22 \mathrm{~nm})$. The similarity of the surface topographies of the two surfaces is further illustrated in the height histograms shown in Figure 1c where no distinct differences can be observed. In the context of transistors, this feature is crucial for effective charge carrier accumulation and transport at the critical dielectric/semiconductor interface. This is particularly true for top-gate transistor architecture where the surface topography defines the morphology of the actual conducting channel. ${ }^{41}$

\subsection{Transistor Design and Electrical Characterisation}

The charge transport properties of the $\mathrm{PC}_{61} \mathrm{BM}$ layers were investigated in $\mathrm{TG}-\mathrm{BC}$ transistor architectures (Figure 2a). To achieve ambipolar transport, efficient injection of both electrons and holes from the S-D electrodes to the corresponding energy levels in the semiconductor, is essential. The latter requires good energy level alignment between the electrode(s) and the semiconductor. This can be, at least partially, accomplished using polar molecules that can self-assemble on the electrode's surface forming a highly-ordered dipole layer. Such selfassembled monolayers (SAMs) have been used as electrode work function modifiers, which under certain circumstances can lead to enhanced carrier injection. ${ }^{42-45}$ Herein PFBT was chosen as the work function modifier for the Au S-D electrodes (Figure 2a). A schematic depiction of the various steps used to functionalise the PFBT on the surface of the Au electrodes, 
is shown in Figure S1. Figure $\mathbf{2 b}$ shows the simplified energy-band diagram of $\mathrm{PC}_{61} \mathrm{BM}$ and Au electrode before and after PFBT application. The mismatch in the work function of Au and the highest occupied molecular orbital (HOMO) of $\mathrm{PC}_{61} \mathrm{BM}$ before contact results in an injection barrier of $\approx 0.9 \mathrm{eV}$ for holes. The actual mismatch, however, is known to further increase due to the formation of a strong dipole layer at the $\mathrm{Au} / \mathrm{PC}_{61} \mathrm{BM}$ interface, ${ }^{46}$ leading to a large injection barrier for holes. In an effort to address this issue we treated Au with PFBT, which resulted to a reduction of the electrodes' work function by $\approx 1 \mathrm{eV}$ (Au/PFBT in Figure. 2b). This shift towards the $\mathrm{HOMO}$ of $\mathrm{PC}_{61} \mathrm{BM}$ makes $\mathrm{Au} / \mathrm{PFBT}$ a potentially good holeinjecting electrode. Apart from charge injection, carrier trapping at the dielectric/semiconductor interface, which originates from impurities or certain chemical moieties, ${ }^{47}$ is also known to limit the carrier mobility and presents an additional challenge for achieving balanced ambipolar charge transport. To address this issue the fluoropolymer CYTOP was selected as the gate dielectric. The formulation of this hydroxyl-free polymer is orthogonal to the underlying $\mathrm{PC}_{61} \mathrm{BM}$ and is known to lead to the formation of a trap-free semiconductor-dielectric interface for holes and electrons. ${ }^{48,49}$

Figure 2c and $\mathbf{2 d}$ show the transfer characteristics measured in the dark for a $\mathrm{PC}_{61} \mathrm{BM}$ transistor using negative and positive drain $\left(\mathrm{V}_{\mathrm{D}}\right)$ and gate $\left(\mathrm{V}_{\mathrm{G}}\right)$ voltages, respectively. In both bias modes the device exhibits typical V-shaped characteristics indicative of hole and electron accumulation in the channel. Figures $2 \mathbf{e}$ and $\mathbf{2 f}$ show the corresponding output characteristics of the same transistor in hole-enhancement and electron-enhancement bias regimes, respectively. At high $V_{\mathrm{G}}$ the transistor shows linear-to-saturation curves that resemble closely those of unipolar devices. At low $V_{\mathrm{G}}$, however, a super-linear current increase is observed, especially in the high $V_{\mathrm{D}}$ region due to the injection of minority carriers ${ }^{9}$, a feature that is absent in unipolar transistors. The nonlinear increase in the drain current $\left(I_{\mathrm{D}}\right)$ at small $\mathrm{V}_{\mathrm{D}}$ indicates the presence of injection barriers from $\mathrm{Au} / \mathrm{PFBT} \mathrm{S}-\mathrm{D}$ electrodes to $\mathrm{PC}_{61} \mathrm{BM}$ for both holes and 
electrons. Despite this, the extracted field-effect mobility for holes and electrons extracted in the linear operating regime $\left(V_{\mathrm{D}}= \pm 80 \mathrm{~V}\right.$ and $\left.V_{\mathrm{G}}= \pm 200 \mathrm{~V}\right)$ are high and on the order of 0.06 $\mathrm{cm}^{2} / \mathrm{Vs}$ and $0.14 \mathrm{~cm}^{2} / \mathrm{Vs}$, respectively. These measurements are extremely revealing as they provide direct evidence of the ambipolar nature of $\mathrm{PC}_{61} \mathrm{BM}$, a property that has remained elusive until now.

\subsection{Optoelectronic Characterisation of $\mathrm{PC}_{61} \mathrm{BM}$ Transistors}

Optoelectronic characterization of all transistors was carried out by illuminating the devices with an UV LED with an EL peak at $395 \mathrm{~nm}$ since at these wavelengths $\mathrm{PC}_{61} \mathrm{BM}$ exhibits strong absorption (Figure S2). The corresponding transfer and output curves of ambipolar $\mathrm{PC}_{61} \mathrm{BM}$ phototransistor in electron enhancement mode under different illumination intensity $E_{\text {opt, }}$ are shown in Figure 3a-c. The channel current of the device is found to increase with increasing light intensity indicative of a strong photoresponse. The magnitude of the current increase depends on both the illumination intensity and applied $V_{\mathrm{G}}$. These measurements suggest that additional charges are introduced in the channel upon optical stimulation. One possible photogeneration mechanism is via exciton formation within $\mathrm{PC}_{61} \mathrm{BM}$. These are then dissociated into free electrons and holes that drift to the corresponding electrodes (S or D) due to the applied electrical field $\left(V_{\mathrm{G}}, V_{\mathrm{D}}\right) .{ }^{50}$ Interestingly, the photocurrent enhancement occurs not only in the unipolar operating regime (i.e. $V_{\mathrm{G}}=120 \mathrm{~V}$; Figure $3 \mathbf{b}$ ) but also in the ambipolar regime $\left(V_{\mathrm{G}}=80 \mathrm{~V}\right.$ for $V_{\mathrm{D}}>150 \mathrm{~V}$; Figure 3c) of the transistor. This observation supports the existence of an appreciable photoconductivity component within the channel region. Overall, the results demonstrate that the incident UV light has a strong gating effect that can modulate the channel current independently. 
The performance characteristics of the $\mathrm{PC}_{61} \mathrm{BM}$ phototransistors were further analyzed by quantifying important photodetector parameters including, photosensitivity $P$, responsivity $R$ (in $\mathrm{A} / \mathrm{W}$ ) and specific detectivity $D^{*}$ (in Jones) under different illumination intensities. Figure 4 displays the dependence of these figures of merits as a function of gate voltage $V_{\mathrm{G}}$ and incident optical power $P_{\text {opt. }}$ The $P$, which is the ratio of photo-generated current to the dark current, represents the relative change in channel current with respect to the dark current. Figure 4a shows the evolution of $P$ with $V_{\mathrm{G}}$ where a peak value of $9 \times 10^{3}$ is measured for an illumination intensity of $2.356 \mathrm{~mW} / \mathrm{cm}^{2}$ at $V_{\mathrm{G}}=35 \mathrm{~V}$. This is due to that fact that at this particular $V_{\mathrm{G}}$ bias the channel current is turn-off and $I_{\text {dark }}$ becomes minimum, hence leading to a maximum $P$ value. The decreasing $P$ value with increasing $V_{\mathrm{G}}$, on the other hand, indicates that at higher $V_{\mathrm{G}}$ the channel current is primarily due to injected charges with the photo-induced carriers becoming less and less dominant. However, the increasing $P$ with increasing light intensity across the entire $V_{\mathrm{G}}$ range suggests that photo-generated carriers exist even at high $V_{\mathrm{G}}$ bias. The $R$, which is the ratio of change in $I_{\mathrm{D}}$ to the incident $P_{\mathrm{opt}}$, defines the efficiency of optical power converted into measurable electrical photocurrent. The dependence of $R$ on $V_{\mathrm{G}}$ (Figure 4b) shows that the minimum value is achieved at the channel turn-off bias, which is opposite to that seen for $P$ (Figure 4a). The observed increase in $R$ with increasing $V_{\mathrm{G}}$ is attributed to the improved charge photogeneration and transport across the channel. The log$\log$ plot of $R$ as a function of $P_{\mathrm{opt}}$ (Figure 4c) shows that for a given $V_{\mathrm{G}}$ the $R$ decreases with increasing $P_{\mathrm{opt}}$, which is again opposite to the $P$ vs. $P_{\text {opt }}$ trend seen in Figure $4 \mathbf{d}$. The effect is most likely attributed to enhanced photo-induced electron-hole recombination. ${ }^{51}$ The maximum value for $R$ of $3 \times 10^{3} \mathrm{~A} / \mathrm{W}$ is obtained at the lowest light intensity of $0.007 \mathrm{~mW} / \mathrm{cm}^{2}$. Notably, this value is one order of magnitude higher than that reported for Si phototransistors $(\approx 300 \mathrm{~A} / \mathrm{W})$ and highlights the potential of $\mathrm{PC}_{61} \mathrm{BM}$ phototransistors. ${ }^{52}$ The specific detectivity $D^{*}$ describes the sensitivity of a photodetector with respect to noise and enables direct 
comparison of devices with different areas and geometries. A simple estimation of the specific detectivity according to Eq. 4 is the shot-noise limited detectivity $D_{s}{ }^{*}$. The dependence of $D_{s}{ }^{*}$ on $V_{\mathrm{G}}$ shown in Figure 4e reveals two distinct regions; a peak value calculated at around $V_{\mathrm{G}}=$ $35 \mathrm{~V}$, followed by a continuous increase and saturation for higher $V_{\mathrm{G}}$. The sharp increase of $D_{s}{ }^{*}$ seen at $\mathrm{V}_{\mathrm{G}}=35 \mathrm{~V}$ is attributed to the low background noise level at that particular bias due to the supressed channel current. Specifically, the shot noise, which is proportional to $I_{\mathrm{dark}}$, reaches the lowest level when the channel current is turn-off $\left(\mathrm{V}_{\mathrm{G}}=35 \mathrm{~V}\right)$, resulting in the observed maximum value of $D_{s}{ }^{*}$. The upward trend of $D_{s}{ }^{*}$ with increasing $V_{\mathrm{G}}$, on the other hand, is attributed to the improved current amplification due to the increase of the carrier mobility with increasing $V_{\mathrm{G}}$. The downwards trend of $D_{s}{ }^{*}$ versus $P_{\text {opt }}$ (Figure 4f), which is similar to that of the $R$, is evident in good agreement with Eq. 4. Interestingly, devices characterised in the on-state exhibit a higher $D_{s} *$ at low $P_{\text {opt, }}$ whereas those measured in the off-state show a higher $D_{s}{ }^{*}$ at high $P_{\text {opt. }}$. We believe this to be due to the difference in the current amplification as a result of the different operating/illuminating regimes. A key conclusion that can be reached from these measurements is that in order to fully exploit the signal gain mechanism in these ambipolar $\mathrm{PC}_{61} \mathrm{BM}$ phototransistors the device needs to be operated at low $P_{\text {opt. }}$ Only then, the maximum value for $D_{s}{ }^{*}$ of $1.3 \times 10^{13}$ Jones can be achieved. We note that the latter is comparable to that measured for Si photodetectors $\left(\approx 4 \times 10^{12}\right.$ Jones $) .{ }^{18}$

In an effort to understand the different contributions in the photo-detection mechanism(s), we monitored the channel current of the transistors both in the off-state $\left(I_{\mathrm{D}(\mathrm{Ph}-}\right.$ OFF) $)$ and on-state $\left(I_{\mathrm{D}(\mathrm{Ph}-\mathrm{ON})}\right)$ as a function of $P_{\mathrm{opt}}$ (Figure 5). The result suggests two primary photodetection mechanisms, namely photovoltaic and photoconductive effects. These processes are similar to those observed in both inorganic ${ }^{53}$ and organic ${ }^{14,39}$ phototransistors, highlighting the similarities in the operating principles. In the case of photovoltaic effect, photo-generated carriers within the channel tend to lower the injection barrier and associated 
contact resistance as well as directly contributing to free charges in the channel. Both processes can lead to a measurable shift in the threshold voltage $\left(V_{\mathrm{T}}\right)$, resulting in a significant increase in channel current even under low illumination intensities. The photocurrent induced by the photovoltaic effect is given by ${ }^{54}$ :

$$
I_{p v}=g_{m} \Delta V_{t h}=\frac{A k T}{q} \ln \left(1+\frac{\eta q \lambda P_{o p t}}{I_{\text {dark }} h c}\right)
$$

where, $g_{\mathrm{m}}$ is the transconductance, $\Delta V_{\mathrm{TH}}$ is the threshold voltage shift, $A$ is the fitting parameter, $\eta$ is the photogeneration quantum efficiency, $I_{\text {dark }}$ is the dark current for minority charges and $h c / \lambda$ is the energy of the incident photons. In the case of photoconductive effect, photo-induced bound electrons and holes are separated and transferred directly by the external applied field, the channel current therefore increases linearly with the incident power. The photocurrent caused by the photoconductive effect can be expressed as ${ }^{55}$ :

$$
I_{p c}=\left(q \mu_{p} p E\right) W D=B P_{o p t}
$$

where, $\mu_{\mathrm{p}}$ is the hole mobility, $p$ is the hole concentration, $E$ is the electric field in the channel, $W$ is the channel width, $D$ is the depth of the absorption region, and $B$ is the fitting parameter. In Figure 5, the photocurrents measured in both the on- and off-state for a fixed $V_{D}$ of $80 \mathrm{~V}$ are plotted as a function of $P_{\text {opt. }}$ Here symbols denote the experimental results while solid lines represent the fittings to the data using Eqs. 5 and 6. The fittings were performed assuming that the photocurrent is the result of a synergistic effect of the two mechanisms. The results indicate that the photoconductive effect dominates the device operation in the off-state while the photovoltaic effect becomes dominant in the on-state. This is an interesting finding as it provides direct evidence of the photogeneration mechanisms in ambipolar phototransistors.

The detection capabilities of the ambipolar $\mathrm{PC}_{61} \mathrm{BM}$ phototransistor across a wider range of visible wavelengths, have also been investigated. Figure 6a shows the absorption 
spectra of $\mathrm{PC}_{61} \mathrm{BM}$ together with the electroluminescence spectrum of the different LEDs employed as the light sources (with peak emission wavelengths of $\lambda_{\mathrm{B}}=475 \mathrm{~nm}, \lambda_{\mathrm{G}}=525 \mathrm{~nm}$, $\left.\lambda_{\mathrm{R}}=632 \mathrm{~nm}\right)$. The transfer characteristics of devices measured in dark and under different illumination intensities with the different LEDs are shown in Figure 6b. Clear device photoresponse is evident for all three wavelengths with the blue light $\left(\lambda_{B}=475 \mathrm{~nm}\right)$ illuminated transistor exhibiting the highest response and the red light illuminated one $\left(\lambda_{R}=632 \mathrm{~nm}\right)$ the smallest. The level of photoresponse appears to correlate with the overlap between the absorption of $\mathrm{PC}_{61} \mathrm{BM}$ and the EL emission of the individual LEDs (Figure 6a).

Quantitative analysis of the device response to different wavelengths was performed by calculating the $P, R$ and $D^{*}$ parameters (Figure 7a-c) for all wavelengths at constant $P_{\text {opt }}(0.7$ $\left.\mathrm{mW} / \mathrm{cm}^{2}\right)$ and bias $\left(\mathrm{V}_{\mathrm{D}}=80 \mathrm{~V}\right.$ and $\left.\mathrm{V}_{\mathrm{G}}=35 \mathrm{~V}\right)$ conditions. Evidently, all three parameters improve as the wavelength of the incident light reduces from $632 \mathrm{~nm}$ (red) to $395 \mathrm{~nm}$ (UV-A). These demonstrate that $\mathrm{PC}_{61} \mathrm{BM}$ phototransistors function as filter-less UV-A $(315-400 \mathrm{~nm})$ photodetectors that combine high sensitivity with simple device architecture.

\subsection{Dynamic Operation of PC 61 BM Phototransistors}

For the successful deployment of any emerging photodetector technology to commercial products the sensor should not only offer high sensitivity and spectra selectivity but also good temporal response. To investigate the dynamic response of our $\mathrm{PC}_{61} \mathrm{BM}$ phototransistor, the switching behaviour of optimized devices was investigated. This was achieved by exposing the devises to light pulses and monitoring the evolution of the channel current in real time using the measurement setup shown in Figure 8a. During the measurements the transistor was maintained at a constant bias of $V_{\mathrm{D}}=80 \mathrm{~V}$ and $V_{\mathrm{G}}=35 \mathrm{~V}$. Figure $8 \mathbf{b}$ shows the temporal response of the channel current to a train of light pulses $10 \mathrm{~ms}$ long. The rise time, $t_{\mathrm{R}}$, (current 
increasing from $10 \%$ to $90 \%$ of the maximum value) and the fall time, $t_{\mathrm{F}}$, (current decreasing from $90 \%$ to $10 \%$ of its maximum value) were then calculated directly from Figure $8 \mathbf{c}$ yielding values of $t_{\mathrm{R}}=0.94 \mathrm{~ms}$ and $t_{\mathrm{F}}=1.02 \mathrm{~ms}$, respectively, as well as a total response time of $\sim 2 \mathrm{~ms}$. To this end we note that the latter value approaches the detection limit of our measurement setup due to the necessary trade-off between small-signal detection (nA) and the effective signal bandwidth of the current amplifier (CA). Despite this, however, the results show that our $\mathrm{PC}_{61} \mathrm{BM}$ phototransistors are faster than most of the unipolar organic phototransistors reported to date and compare favourably to the ultrafast quantum dot (QD), low-dimensional and/or hybrid photodetectors. ${ }^{56-70}$ The fast temporal response is attributed to the excellent ambipolar transport characteristics of $\mathrm{PC}_{61} \mathrm{BM}$, and the resulting efficient carrier generation and transport across the channel. Finally, our results highlight the use of single organic ambipolar semiconductors as a promising approach to the development of fast phototransistors with tailored photoresponse.

\section{CONCLUSIONS}

$\mathrm{UV}$-sensitive phototransistors based on the solution-processed methanofullerene $\mathrm{PC}_{61} \mathrm{BM}$ have been fabricated and characterised. The carefully engineered devices exhibit balanced ambipolar transport in the dark with electron and hole mobility values of 0.14 and $0.06 \mathrm{~cm}^{2} / \mathrm{Vs}$, respectively. Due to the light absorption characteristics of $\mathrm{PC}_{60} \mathrm{BM}$ the resulting devices exhibit large photoresponse particularly in the UVA region of the electromagnetic spectrum. Importantly, the $\mathrm{PC}_{60} \mathrm{BM}$ phototransistors are able to operate at high frequencies with minimum response times of less than $2 \mathrm{~ms}$, in spite the long channel length ( $30 \mu \mathrm{m})$ employed - a temporal response difficult to achieve in conventional unipolar organic-based phototransistors. To this end, the performance parameters extracted under low illumination 
intensities are comparable to those of Si-based photodetectors, mainly due to the intrinsic gain mechanism associated with the three-terminal phototransistor architecture. This work highlights the use of single material ambipolar organic phototransistors as promising concept for the development of fast photodetectors with tailored colour sensitivity and high specific detectivity.

\section{Supporting Information}

Schematic of the processing steps employed to fabricate the transistors, absorption characteristics of $\mathrm{PC}_{61} \mathrm{BM}$ films and the electroluminescence spectra of the inorganic ultraviolet LED employed. This material is available free of charge via the Internet at http://pubs.acs.org 


\section{FIGURES}

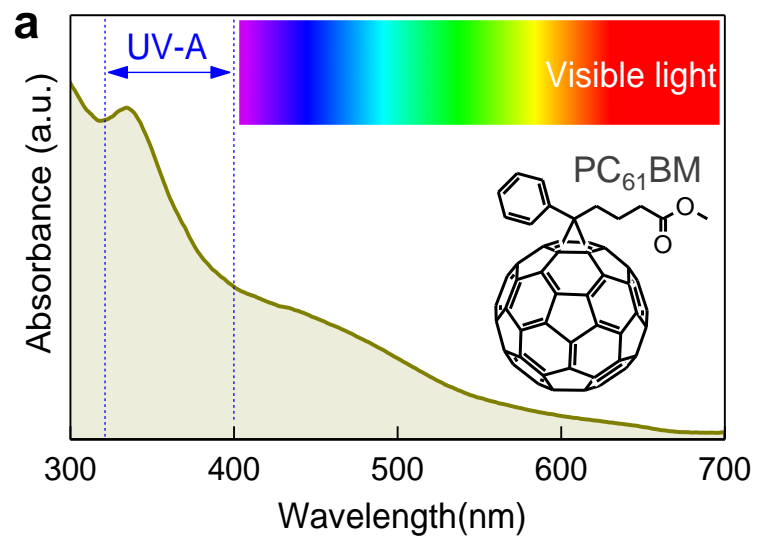

b

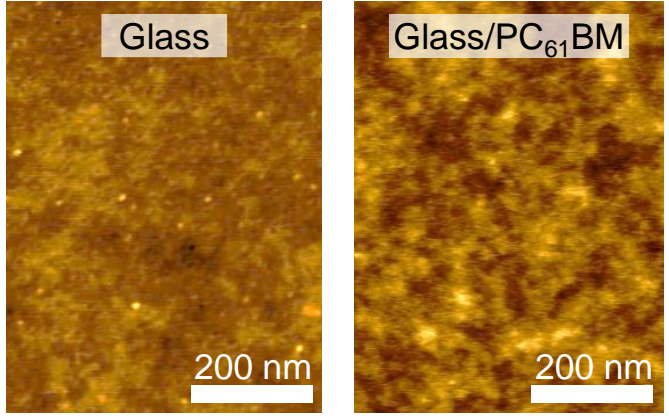

C

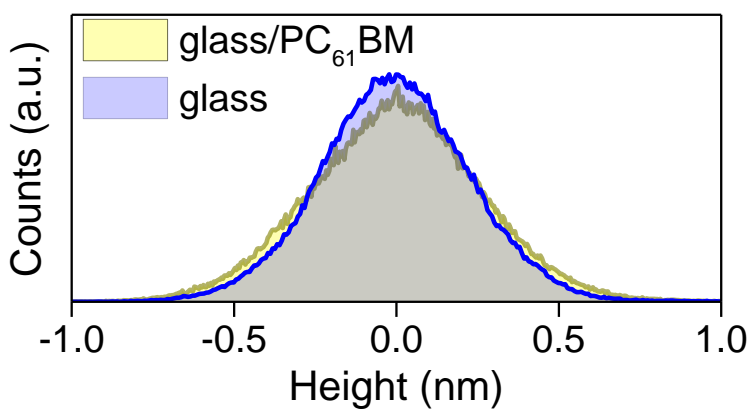

Figure 1. (a) UV-Vis absorption spectrum of a $\mathrm{PC}_{61} \mathrm{BM}$ layer deposited on quartz substrate via spin coating. Inset shows the molecular structure of $\mathrm{PC}_{61} \mathrm{BM}$. (b) $\mathrm{AFM}$ images of the surface topography of bare glass and $\mathrm{PC}_{61} \mathrm{BM}$ deposited on glass. The root-mean-square (RMS) surface roughness of the glass and glass $/ \mathrm{PC}_{61} \mathrm{BM}$ samples are 0.22 and $0.26 \mathrm{~nm}$, respectively. (c) Height distribution histogram extracted from the AFM images in (b). 
a

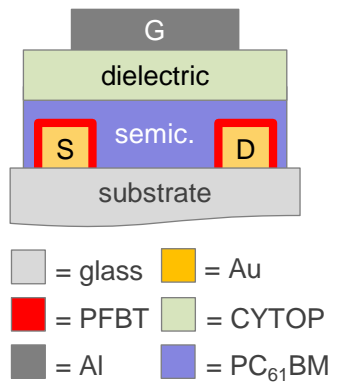

b

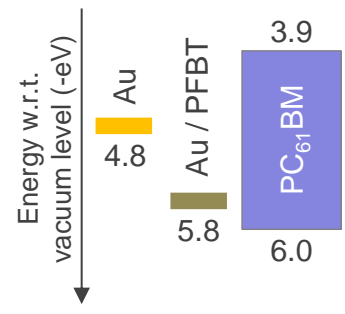

C

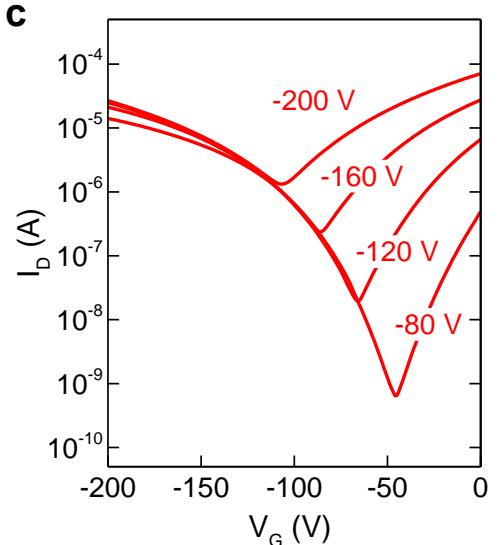

e

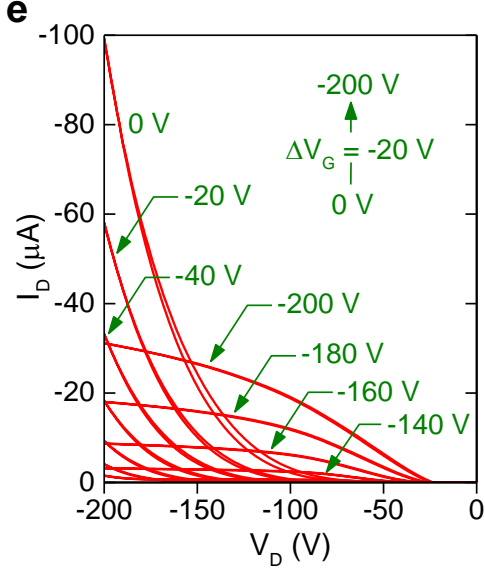

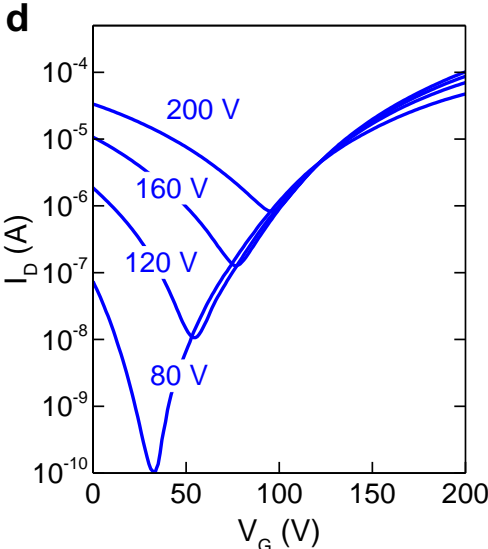

f

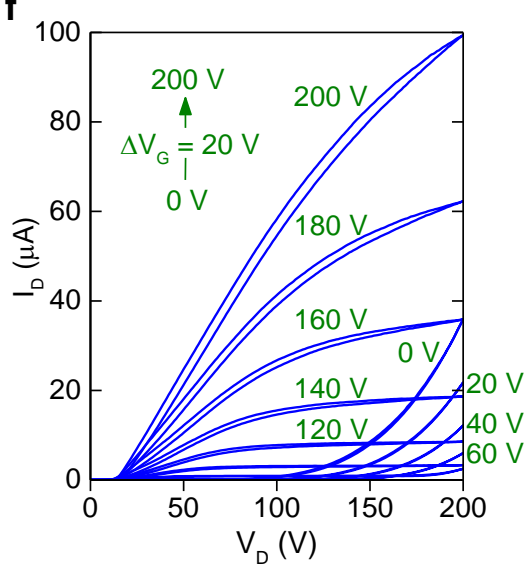

Figure 2. (a) A schematic of the top-gate, bottom-contact (TG-BC) transistor architecture developed in this study. (b) Energy level band diagram for $\mathrm{PC}_{61} \mathrm{BM}$, gold ( $\mathrm{Au}$ ) electrode and PFBT-treated $\mathrm{Au}$ electrode $(\mathrm{Au} / \mathrm{PFBT})$. Transfer characteristics measured for a $\mathrm{PC}_{61} \mathrm{BM}$ transistor in hole accumulation (c) and electron accumulation (d) bias regimes. Output characteristics measured for the same $\mathrm{PC}_{61} \mathrm{BM}$ transistor obtained in hole (e) and electron (f) accumulation. 
a

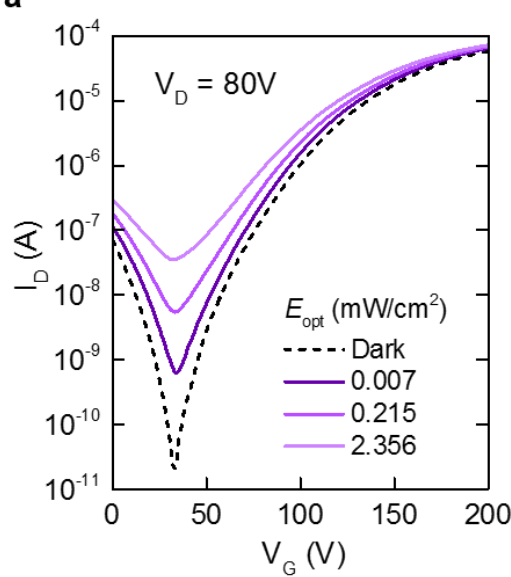

b

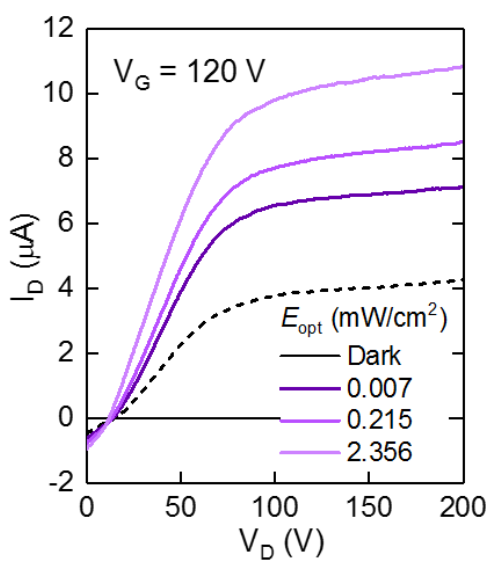

C

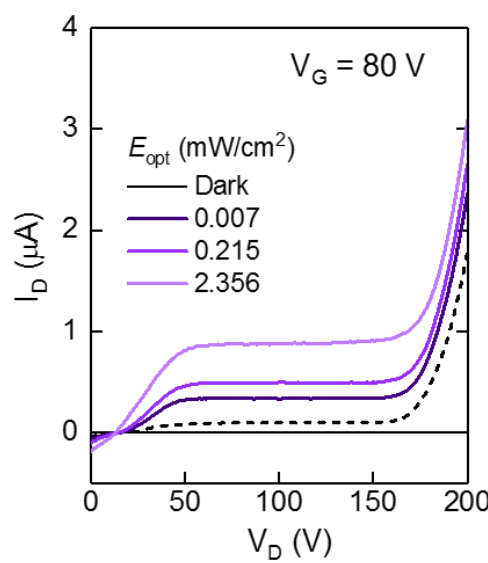

Figure 3. (a) Transfer characteristics of a $\mathrm{PC}_{61} \mathrm{BM}$ phototransistor measured at fixed $V_{\mathrm{D}}=80$ V (electron accumulation) in the dark and under UV illumination of different intensities. (b) Output characteristics measured for the same $\mathrm{PC}_{61} \mathrm{BM}$ transistor at $V_{\mathrm{G}}=120 \mathrm{~V}$ (electron accumulation regime). (c) Output characteristics of the same $\mathrm{PC}_{61} \mathrm{BM}$ transistor measured at $V_{\mathrm{G}}=80 \mathrm{~V}$ (ambipolar transport regime) under dark and UV illumination at various intensities. 

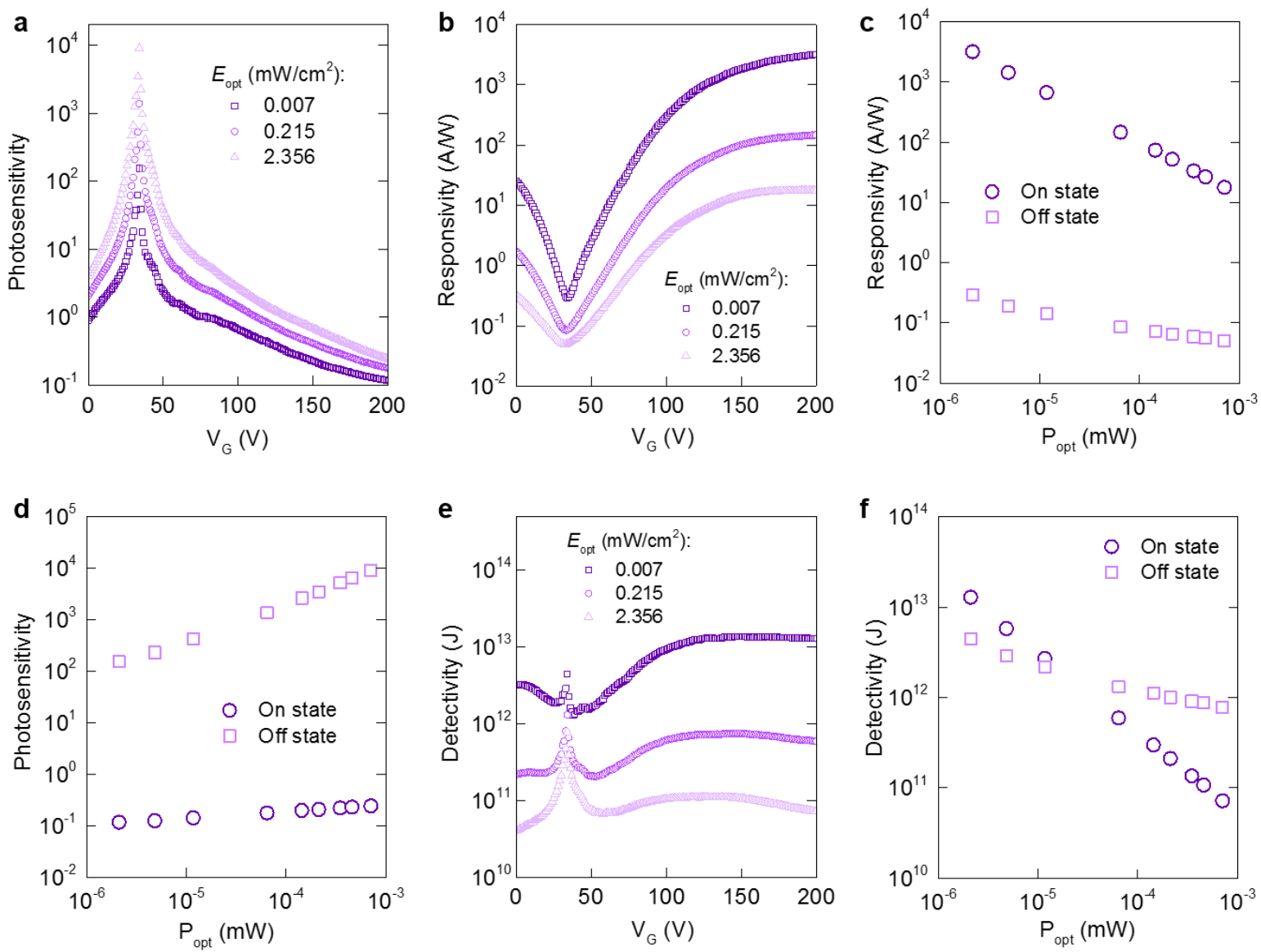

Figure 4. Optoelectronic characterization of $\mathrm{PC}_{61} \mathrm{BM}$ phototransistor. (a) Photosensitivity $(P)$, and (b) responsivity $(R)$ versus $V_{\mathrm{G}}$ measured at a constant $V_{\mathrm{D}}=80 \mathrm{~V}$ and at three different illumination intensities. (c) $R$ and (d) $P$ versus incident optical power $\left(P_{\text {opt }}\right)$ measured at two different channel biasing regimes: on-state $\left(V_{\mathrm{G}}=200 \mathrm{~V}\right)$ and off-state $\left(V_{\mathrm{G}}=35 \mathrm{~V}\right)$ at fixed $V_{\mathrm{D}}$ $=80 \mathrm{~V}$. (e) shot-noise limited specific detectivity $\left(D_{s}{ }^{*}\right)$ versus $V_{\mathrm{G}}$ measured at three different illumination intensities and at a fixed $V_{\mathrm{D}}=80 \mathrm{~V}$. (f) $D_{s}{ }^{*}$ versus $P_{\text {opt }}$ measured for the same $\mathrm{PC}_{61} \mathrm{BM}$ phototransistor at two different channel biasing regimes: on-state $\left(V_{\mathrm{G}}=200 \mathrm{~V}\right)$ and off-state $\left(V_{\mathrm{G}}=35 \mathrm{~V}\right)$ at fixed $V_{\mathrm{D}}=80 \mathrm{~V}$. 


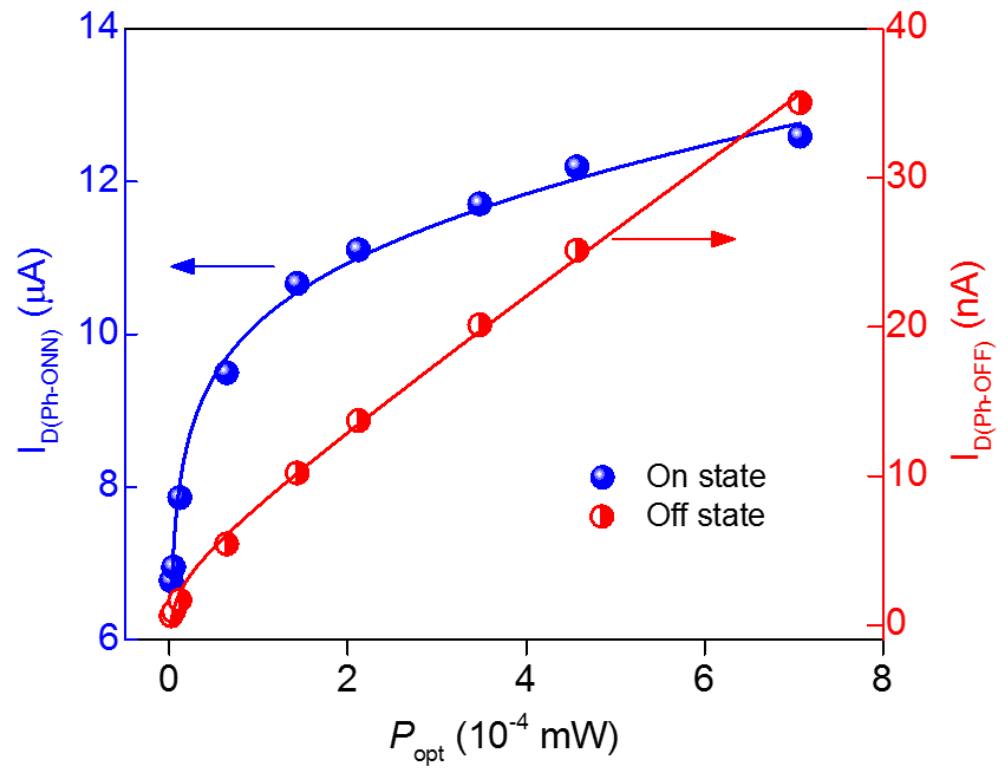

Figure 5. Evolution of the channel photocurrent as a function of incident optical power $\left(P_{\mathrm{opt}}\right)$ in measured for a $\mathrm{PC}_{61} \mathrm{BM}$ phototransistor in the on-state $\left(V_{\mathrm{G}}=200 \mathrm{~V}\right)$ and in the off-state $\left(V_{\mathrm{G}}\right.$ $=35 \mathrm{~V})$ at a constant $V_{\mathrm{D}}=80 \mathrm{~V}$. The symbols represent experimental measured data whilst the solid lines are the fitting curves. 
a

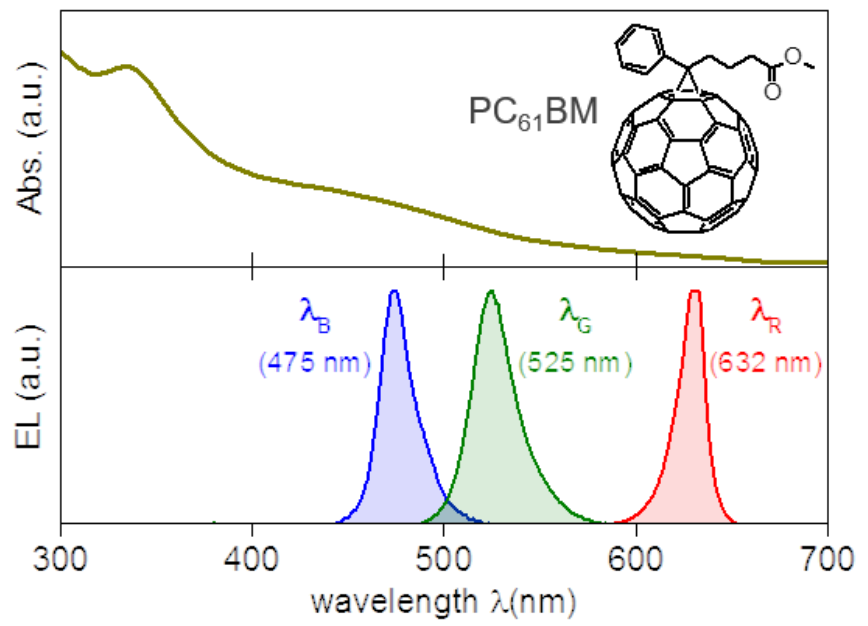

\section{b}

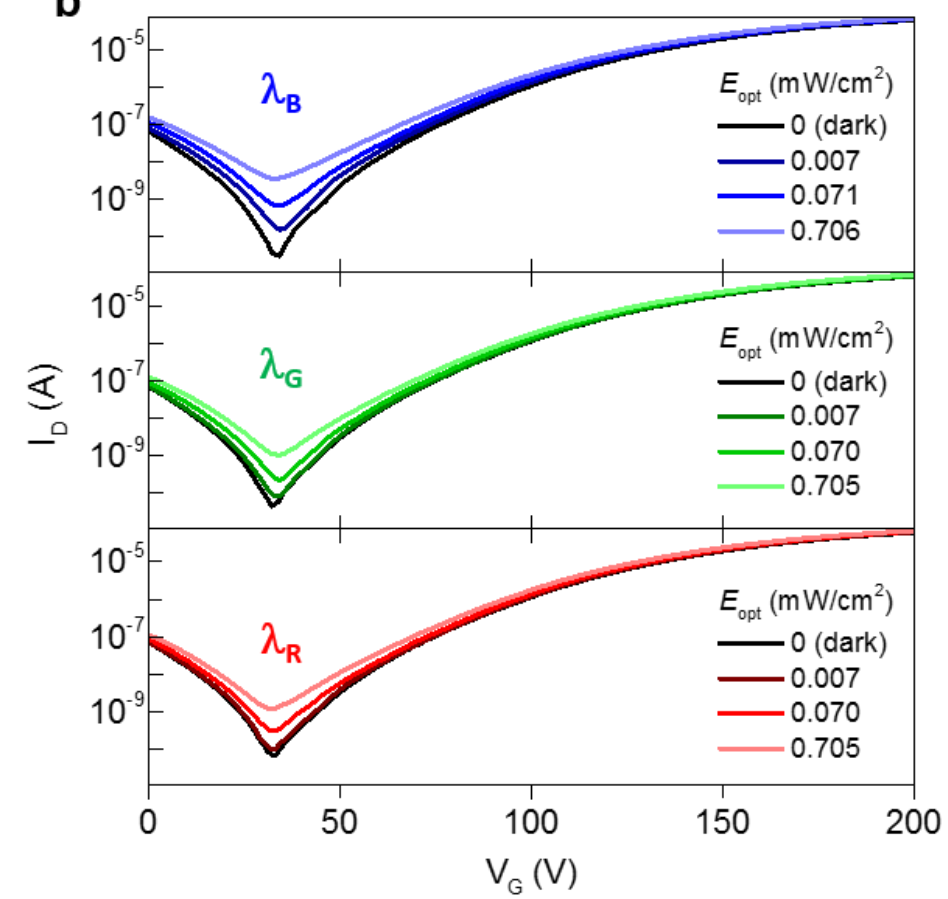

Figure 6. (a) Absorption and $\mathrm{EL}$ spectra of the $\mathrm{PC}_{61} \mathrm{BM}$ layer and for the three visible light LEDs used to perform the photoresponse measurements. (b) Transfer characteristics measured for a $\mathrm{PC}_{61} \mathrm{BM}$ phototransistor illuminated with blue light $\left(\lambda_{\mathrm{B}}=475 \mathrm{~nm}\right)$, green light $\left(\lambda_{\mathrm{G}}=525\right.$ $\mathrm{nm})$ and red light $\left(\lambda_{\mathrm{R}}=632 \mathrm{~nm}\right)$ at different intensities $\left(P_{\mathrm{opt}}\right)$. The black curves in each plot represent the transfer characteristics measured in dark at $V_{\mathrm{D}}=80 \mathrm{~V}$. 


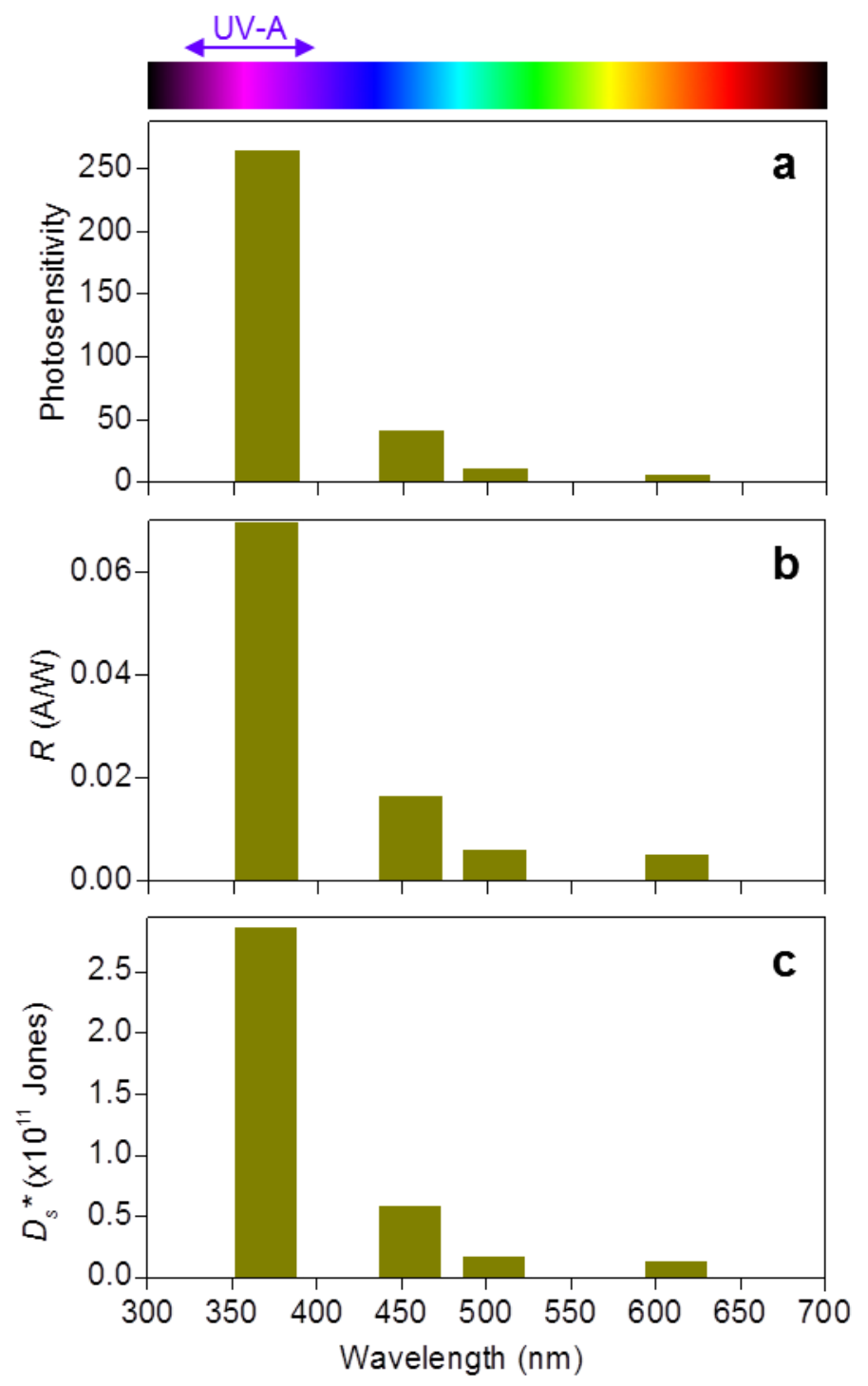

Figure 7. Calculated values for $P(\mathbf{a}), R(\mathbf{b})$, and $D_{s}{ }^{*}$ (c) for all four different wavelengths investigated. All parameters were calculated from the transfer characteristics of the same $\mathrm{PC}_{61} \mathrm{BM}$ phototransistor biased at $V_{\mathrm{G}}=35 \mathrm{~V}$, and $V_{\mathrm{D}}=80 \mathrm{~V}$, and illuminated with $E_{\mathrm{opt}}=0.706$ $\mathrm{mW} / \mathrm{cm}^{2}$. 
a

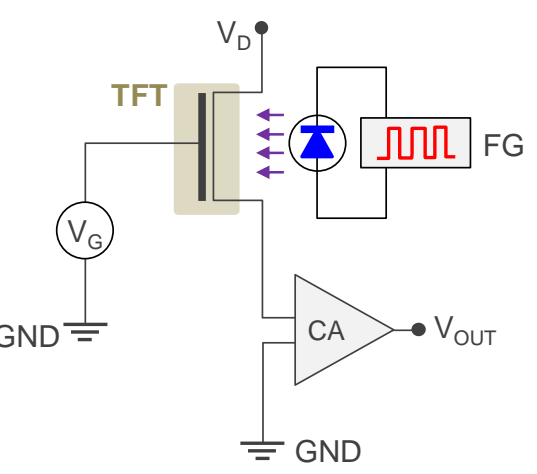

b

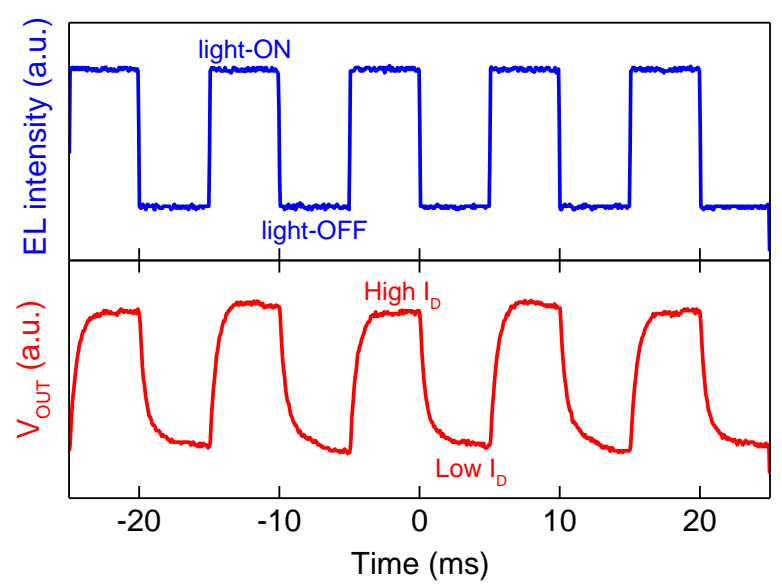

C
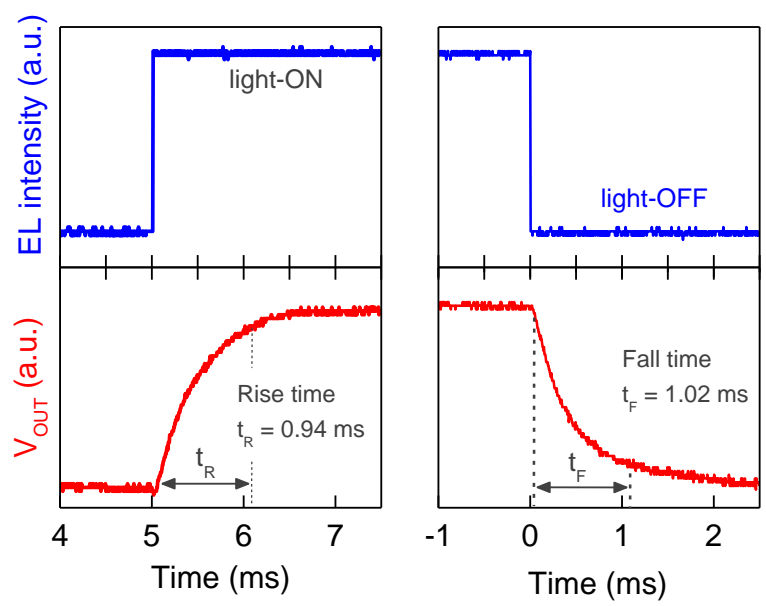

Figure 8. (a) Circuitry of the experimental setup used for the dynamic characterisation of the $\mathrm{PC}_{61} \mathrm{BM}$ phototransistors. A function generator $(\mathrm{FG})$ is used to drive the LED. The channel current in the transistor, which is biased at $V_{\mathrm{G}}=35 \mathrm{~V}$ and $V_{\mathrm{D}}=80 \mathrm{~V}$, is monitored in real time using a current amplifier (CA) and recorded as a voltage ( $\left.\mathrm{V}_{\text {OUT }}\right)$ using an oscilloscope. (b) Response of the channel current (red trace) to a train of blue $\left(\lambda_{\max }=475 \mathrm{~nm}\right)$ light pulses with $E_{\mathrm{opt}}=0.744 \mathrm{~mW} / \mathrm{cm}^{2}$ (blue trace). (c) Analysis of raise $\left(t_{\mathrm{R}}\right)$ and fall $\left(t_{\mathrm{F}}\right)$ times. 


\section{AUTHOR INFORMATION}

Corresponding Author: *E-mail: thomas.anthopoulos@kaust.edu.sa. Corresponding author address: King Abdullah University of Science and Technology (KAUST), Division of Physical Sciences and Engineering, Thuwal 23955-6900, Saudi Arabia.

\section{Author Contributions}

The work reported here was supported by the King Abdullah University of Science and Technology (KAUST). W.H., Y-H.L., and T.D.A. designed the experiments analysed the experimental data and wrote the article. W.H., and Y-H.L., carried out the experimental work. All authors have given approval to the final version of the manuscript. 


\section{REFERENCES}

(1) Drury, C. J.; Mutsaers, C. M. J.; Hart, C. M.; Matters, M.; de Leeuw, D. M. Low-Cost All-Polymer Integrated Circuits. Appl. Phys. Lett. 1998, 73 (1), 108-110.

(2) Gelinck, G. H.; Huitema, H. E. a; van Veenendaal, E.; Cantatore, E.; Schrijnemakers, L.; van der Putten, J. B. P. H.; Geuns, T. C. T.; Beenhakkers, M.; Giesbers, J. B.; Huisman, B.-H.; Meijer, E. J.; Benito, E. M.; Touwslager, F. J.; Marsman, A. W.; van Rens, B. J. E.; de Leeuw, D. M. Flexible Active-Matrix Displays and Shift Registers Based on Solution-Processed Organic Transistors. Nat. Mater. 2004, 3 (2), 106-110.

(3) Bao, Z. N.; Feng, Y.; Dodabalapur, A.; Raju, V. R.; Lovinger, A. J. High-Performance Plastic Transistors Fabricated by Printing Techniques. Chem. Mater. 1997, 9 (24), $1299-1301$.

(4) Forrest, S. R. The Path to Ubiquitous and Low-Cost Organic Electronic Appliances on Plastic. Nature 2004, 428 (6986), 911-918.

(5) Dong, H.; Zhu, H.; Meng, Q.; Gong, X.; Hu, W. Organic Photoresponse Materials and Devices. Chem. Soc. Rev. 2012, 41 (5), 1754-1808.

(6) Meijer, E. J.; de Leeuw, D. M.; Setayesh, S.; van Veenendaal, E.; Huisman, B. H.; Blom, P. W. M.; Hummelen, J. C.; Scherf, U.; Kadam, J.; Klapwijk, T. M. SolutionProcessed Ambipolar Organic Field-Effect Transistors and Inverters. Nat. Mater. 2003, 2 (10), 678-682.

(7) Anthopoulos, T. D.; De Leeuw, D. M.; Cantatore, E.; Setayesh, S.; Meijer, E. J.; Tanase, C.; Hummelen, J. C.; Blom, P. W. M. Organic Complementary-like Inverters Employing Methanofullerene-Based Ambipolar Field-Effect Transistors. Appl. Phys. Lett. 2004, 85 (18), 4205-4207.

(8) Crone, B.; Dodabalapur, A.; Filas, R. W.; Bao, Z.; Katz, H. E.; Li, W. Large-Scale Complementary Integrated Circuits Based on Organic Transistors. 2000, 521-523. 
(9) Smits, E.; Anthopoulos, T.; Setayesh, S.; van Veenendaal, E.; Coehoorn, R.; Blom, P.; de Boer, B.; de Leeuw, D. Ambipolar Charge Transport in Organic Field-Effect Transistors. Phys. Rev. B 2006, 73 (20), 205316.

(10) Wakahara, T.; D’Angelo, P.; Miyazawa, K.; Nemoto, Y.; Ito, O.; Tanigaki, N.; Bradley, D. D. C.; Anthopoulos, T. D. Fullerene/cobalt Porphyrin Hybrid Nanosheets with Ambipolar Charge Transporting Characteristics. J. Am. Chem. Soc. 2012, 134 (17), 7204-7206.

(11) Hepp, A.; Heil, H.; Weise, W.; Ahles, M.; Schmechel, R.; von Seggern, H. LightEmitting Field-Effect Transistor Based on a Tetracene Thin Film. Phys. Rev. Lett. 2003, $91(15), 157406$.

(12) Swensen, J. S.; Soci, C.; Heeger, A. J. Light Emission from an Ambipolar Semiconducting Polymer Field-Effect Transistor. Appl. Phys. Lett. 2005, 87 (25), 253511.

(13) Smits, E. C. P.; Setayesh, S.; Anthopoulos, T. D.; Buechel, M.; Nijssen, W.; Coehoorn, R.; Blom, P. W. M.; De Boer, B.; De Leeuw, D. M. Near-Infrared Light-Emitting Ambipolar Organic Field-Effect Transistors. Adv. Mater. 2007, 19 (5), 734-738.

(14) Marjanović, N.; Singh, T. B.; Dennler, G.; Günes, S.; Neugebauer, H.; Sariciftci, N. S.; Schwödiauer, R.; Bauer, S. Photoresponse of Organic Field-Effect Transistors Based on Conjugated Polymer/fullerene Blends. Org. Electron. physics, Mater. Appl. 2006, 7 (4), 188-194.

(15) Anthopoulos, T. D.; Wöbkenberg, P. H.; Bradley, D. D. C. Light-Sensing Ambipolar Organic Transistors for Optoelectronic Applications. Proc. SPIE 2008, 6999, 69990X.

(16) Kufer, D.; Konstantatos, G. Photo-FETs: Phototransistors Enabled by 2D and 0D Nanomaterials. ACS Photonics 2016, 3 (12), 2197-2210.

(17) Baeg, K. J.; Binda, M.; Natali, D.; Caironi, M.; Noh, Y. Y. Organic Light Detectors: 
Photodiodes and Phototransistors. Adv. Mater. 2013, 25 (31), 4267-4295.

(18) Gong, X.; Tong, M.; Xia, Y.; Cai, W.; Moon, J. S.; Cao, Y.; Yu, G.; Shieh, C.;

Nilsson, B.; Heeger, A. J. High-Detectivity Polymer Photodetector with Spectral

Response from $300 \mathrm{Nm}$ to $1450 \mathrm{Nm}$. Sci. Reports 2009, 325 (5948), 1665-1667.

(19) Arnold, M. S.; Zimmerman, J. D.; Renshaw, C. K.; Xu, X.; Lunt, R. R.; Austin, C. M.; Forrest, S. R. Broad Spectral Response Using Carbon Nanotube/organic semiconductor/C60 Photodetectors. Nano Lett. 2009, 9 (9), 3354-3358.

(20) Antognazza, M. R.; Scherf, U.; Monti, P.; Lanzani, G. Organic-Based Tristimuli Colorimeter. Appl. Phys. Lett. 2007, 90, 163509.

(21) Nalwa, K. S.; Cai, Y.; Thoeming, A. L.; Shinar, J.; Shinar, R.; Chaudhary, S. Polythiophene-Fullerene Based Photodetectors: Tuning of Spectral Esponse and Application in Photoluminescence Based (Bio)chemical Sensors. Adv. Mater. 2010, 22 (37), 4157-4161.

(22) Gemayel, M. El; Treier, M.; Musumeci, C.; Li, C.; Mullen, K.; Samori, P. Tuning the Photoresponse in Organic Field-Effect Transistors. J. Am. Chem. Soc. 2012, 134 (4), $2429-2433$.

(23) Chikamatsu, M.; Nagamatsu, S.; Yoshida, Y.; Saito, K.; Yase, K.; Kikuchi, K. Solution-Processed N -Type Organic Thin-Film Transistors with High Field-Effect Mobility. Appl. Phys. Lett. 2005, 87, 203504.

(24) Kobayashi, S.; Takenobu, T.; Mon, S.; Fujiwara, A.; Iwasa, Y. Fabrication and Characterization of C60 Thin-Film Transistors with High Field-Effect Mobility. Appl. Phys. Lett. 2003, 82 (25), 4581-4583.

(25) Waldauf, C.; Schilinsky, P.; Perisutti, M.; Hauch, J.; Brabec, C. J. Solution-Processed Organic N-Type Thin-Film Transistors. Adv. Mater. 2003, 15 (24), 2084-2088.

(26) Wobkenberg, P. H.; Bradley, D. D. C.; Kronholm, D.; Hummelen, J. C.; de Leeuw, D. 
M.; Colle, M.; Anthopoulos, T. D. High Mobility N-Channel Organic Field-Effect Transistors Based on Soluble C60 and C70 Fullerene Derivatives. Synth. Met. 2008, $158(11), 468-472$.

(27) Shkunov, M.; Simms, R.; Heeney, M.; Tierney, S.; McCulloch, I. Ambipolar FieldEffect Transistors Based on Solution-Processable Blends of thieno[2,3-B]thiophene Terthiophene Polymer and Methanofullerenes. Adv. Mater. 2005, 17 (21), 2608-2612.

(28) Cho, S.; Yuen, J.; Kim, J. Y.; Lee, K.; Heeger, A. J. Ambipolar Organic Field-Effect Transistors Fabricated Using a Composite of Semiconducting Polymer and Soluble Fullerene. Appl. Phys. Lett. 2006, 89, 153505.

(29) Wei, Q.; Tajima, K.; Hashimoto, K. Bilayer Ambipolar Organic Thin-Film Transistors and Inverters Prepared by the Contact-Film-Transfer Method. ACS Appl. Mater. Interfaces 2009, 1 (9), 1865-1868.

(30) Ma, W.; Yang, C.; Gong, X.; Lee, K.; Heeger, A. J. Thermally Stable, Efficient Polymer Solar Cells with Nanoscale Control of the Interpenetrating Network Morphology. Adv. Funct. Mater. 2005, 15 (10), 1617-1622.

(31) Li, G.; Shrotriya, V.; Huang, J.; Yao, Y.; Moriarty, T.; Emery, K.; Yang, Y. HighEfficiency Solution Processable Polymer Photovoltaic Cells by Self-Organization of Polymer Blends. Nat. Mater. 2005, 4 (11), 864-868.

(32) Kim, Y.; Cook, S.; Tuladhar, S. M.; Choulis, S. A.; Nelson, J.; Durrant, J. R.; Bradley, D. D. C.; Giles, M.; McCulloch, I.; Ha, C.-S.; Ree, M. A Strong Regioregularity Effect in Self-Organizing Conjugated Polymer Films and High-Efficiency Polythiophene:fullerene Solar Cells. Nat. Mater. 2006, 5 (3), 197-203.

(33) Hwang, I. W.; Soci, C.; Moses, D.; Zhu, Z.; Waller, D.; Gaudiana, R.; Brabec, C. J.; Heeger, A. J. Ultrafast Electron Transfer and Decay Dynamics in a Small Band Gap Bulk Heterojunction Material. Adv. Mater. 2007, 19 (17), 2307-2312. 
(34) Scharber, M. C.; Mühlbacher, D.; Koppe, M.; Denk, P.; Waldauf, C.; Heeger, A. J.; Brabec, C. J. Design Rules for Donors in Bulk-Heterojunction Solar Cells - Towards $10 \%$ Energy-Conversion Efficiency. Adv. Mater. 2006, 18 (6), 789-794.

Anthopoulos, T. D.; Tanase, C.; Setayesh, S.; Meijer, E. J.; Hummelen, J. C.; Blom, P. W. M.; De Leeuw, D. M. Ambipolar Organic Field-Effect Transistors Based on a Solution-Processed Methanofullerene. Adv. Mater. 2004, 16 (23-24), 2174-2179.

(36) Choi, W.; Cho, M. Y.; Konar, A.; Lee, J. H.; Cha, G. B.; Hong, S. C.; Kim, S.; Kim, J.; Jena, D.; Joo, J.; Kim, S. High-Detectivity Multilayer MoS2 Phototransistors with Spectral Response from Ultraviolet to Infrared. Adv. Mater. 2012, 24 (43), 5832-5836.

(37) Zhang, W.; Chiu, M.-H.; Chen, C.-H.; Chen, W.; Li, L.; Wee, A. T. S.; Monolayers, W.; Zhang, W.; Chiu, M.-H.; Chen, C.-H.; Chen, W.; Li, L. Role of Metal Contacts in High- Performance Phototransistors Based. ACS Nano 2014, 8 (Xx), 8653-8661.

(38) Liu, X.; Lee, E. K.; Kim, D. Y.; Yu, H.; Oh, J. H. Flexible Organic Phototransistor Array with Enhanced Responsivity via Metal-Ligand Charge Transfer. ACS Appl. Mater. Interfaces 2016, 8 (11), 7291-7299.

(39) Caranzi, L.; Pace, G.; Sassi, M.; Beverina, L.; Caironi, M. Transparent and Highly Responsive Phototransistors Based on a Solution-Processed, Nanometers-Thick Active Layer, Embedding a High-Mobility Electron-Transporting Polymer and a HoleTrapping Molecule. ACS Appl. Mater. Interfaces 2017, 9 (34), 28785-28794.

(40) Ball, J. M.; Bouwer, R. K. M.; Kooistra, F. B.; Frost, J. M.; Qi, Y.; Domingo, E. B.; Smith, J.; De Leeuw, D. M.; Hummelen, J. C.; Nelson, J.; Kahn, A.; Stingelin, N.; Bradley, D. D. C.; Anthopoulos, T. D. Soluble Fullerene Derivatives: The Effect of Electronic Structure on Transistor Performance and Air Stability. J. Appl. Phys. 2011, 110, 14506.

(41) Chua, L.; Zaumseil, J.; Chang, J.; Ou, E. C.-W.; Ho, P. K.-H.; Sirringhaus, H.; Friend, 
R. H. General Observation of N-Type Field-Effect Behaviour in Organic Semiconductors. Nature 2005, 434 (7030), 194-199.

(42) Saudari, S. R.; Frail, P. R.; Kagan, C. R. Ambipolar Transport in Solution-Deposited Pentacene Transistors Enhanced by Molecular Engineering of Device Contacts. Appl. Phys. Lett. 2009, 95, 23301.

(43) De Boer, B.; Hadipour, A.; Mandoc, M. M.; Van Woudenbergh, T.; Blom, P. W. M. Tuning of Metal Work Functions with Self-Assembled Monolayers. Adv. Mater. 2005, $17(5), 621-625$.

(44) Hong, J. P.; Park, A. Y.; Lee, S.; Kang, J.; Shin, N.; Yoon, D. Y. Tuning of Ag Work Functions by Self-Assembled Monolayers of Aromatic Thiols for an Efficient Hole Injection for Solution Processed Triisopropylsilylethynyl Pentacene Organic Thin Film Transistors. Appl. Phys. Lett. 2008, 92, 143311.

(45) Evans, S. D.; Ulman, A. Surface Potential Studies of Alkyl-Thiol Monolayers Adsorbed on Gold. Chem. Phys. Lett. 1990, 170 (5-6), 462-466.

(46) Van Duren, J. K. J.; Mihailetchi, V. D.; Blom, P. W. M.; Van Woudenbergh, T.; Hummelen, J. C.; Rispens, M. T.; Janssen, R. A. J.; Wienk, M. M. Injection-Limited Electron Current in a Methanofullerene. J. Appl. Phys. 2003, 94 (7), 4477-4479.

(47) Zaumseil, J.; Sirringhaus, H. Electron and Ambipolar Transport in Organic FieldEffect Transistors. Chem. Rev. 2007, 107, 1296-1323.

(48) Diemer, P. J.; Lamport, Z. A.; Mei, Y.; Ward, J. W.; Goetz, K. P.; Li, W.; Marcia, M.; Guthold, M.; Anthony, J. E.; Jurchescu, O. D.; Diemer, P. J.; Lamport, Z. A.; Mei, Y.; Ward, J. W.; Goetz, K. P.; Li, W.; Payne, M. M.; Guthold, M.; Anthony, J. E. Quantitative Analysis of the Density of Trap States at the Semiconductor-Dielectric Interface in Organic Field-Effect Transistors Quantitative Analysis of the Density of Trap States at the Semiconductor-Dielectric Interface in Organic Field-Effect Transis. 
Org. Electron. 2015, 107, 103303.

(49) Nugraha, M. I.; Hausermann, R.; Bisri, S. Z.; Matsui, H.; Sytnyk, M.; Heiss, W.; Takeya, J.; Loi, M. A. High Mobility and Low Density of Trap States in Dual-SolidGated PbS Nanocrystal Field-Effect Transistors. Adv. Mater. 2015, 27 (12), 21072112.

(50) Hamilton, M. C.; Martin, S.; Kanicki, J. Thin-Film Organic Polymer Phototransistors. IEEE Trans. Electron Devices 2004, 51 (6), 877-885.

(51) Bube, R. H. Photoelectronic Properties of Semiconductors; Cambridge University Press, 1992.

(52) Johnson, N. M.; Chiang, A. Highly Photosensitive Transistors in Single-Crystal Silicon Thin Films on Fused Silica. Appl. Phys. Lett. 1984, 45 (10), 1102-1104.

(53) Madjar, A.; Herczfeld, P. R.; Paolella, A. Analytical Model for Optically Generated Currents in GaAs MESFETs. IEEE Trans. Microw. Theory Tech. 1992, 40 (8), 16811691.

(54) Romero, M. A.; Martinez, M. A. G.; Herczfeld, P. R. An Analytical Model for the Photodetection Mechanisms in High-Electron Mobility Transistors. IEEE Trans. Microw. Theory Tech. 1996, 44 (12 PART 1), 2279-2287.

(55) Takanashi, Y.; Takahata, K.; Muramoto, Y. Characteristics of InAlAs/InGaAs HighElectron-Mobility Transistors under Illumination with Modulated Light. IEEE Trans. Electron Devices 1999, 46 (12), 2271-2277.

(56) Anthopoulos, T. D. Electro-Optical Circuits Based on Light-Sensing Ambipolar Organic Field-Effect Transistors. Appl. Phys. Lett. 2007, 91 (11), 2005-2008.

(57) Labram, J. G.; Wöbkenberg, P. H.; Bradley, D. D. C.; Anthopoulos, T. D. LowVoltage Ambipolar Phototransistors Based on a pentacene/PC 61BM Heterostructure and a Self-Assembled Nano-Dielectric. Org. Electron. physics, Mater. Appl. 2010, 11 
(7), 1250-1254.

(58) Li, F.; Ma, C.; Wang, H.; Hu, W.; Yu, W.; Sheikh, A. D.; Wu, T. Ambipolar SolutionProcessed Hybrid Perovskite Phototransistors. Nat. Commun. 2015, 6, 8238.

(59) Konstantatos, G.; Badioli, M.; Gaudreau, L.; Osmond, J.; Bernechea, M.; de Arquer, F. P. G.; Gatti, F.; Koppens, F. H. L. Hybrid Graphene-quantum Dot Phototransistors with Ultrahigh Gain. Nat. Nanotechnol. 2012, 7 (6), 363-368.

(60) Yu, H.; Bao, Z.; Oh, J. H. High-Performance Phototransistors Based on SingleCrystalline N-Channel Organic Nanowires and Photogenerated Charge-Carrier Behaviors. Adv. Funct. Mater. 2013, 23 (5), 629-639.

(61) Zhu, M.; Lv, S.; Wang, Q.; Zhang, G.; Lu, H.; Qiu, L. Enhanced near-Infrared Photoresponse of Organic Phototransistors Based on Single-Component Donoracceptor Conjugated Polymer Nanowires. Nanoscale 2016, 8 (14), 7738-7748.

(62) Zhang, H.; Zhang, Y.; Song, X.; Yu, Y.; Cao, M.; Che, Y.; Wang, J.; Yang, J.; Dai, H.; Zhang, G.; Yao, J. High Performance PbSe Colloidal Quantum Dot Vertical Field Effect Phototransistors. Nanotechnology 2016, 27 (42), 425204.

(63) Lee, H. S.; Min, S. W.; Chang, Y. G.; Park, M. K.; Nam, T.; Kim, H.; Kim, J. H.; Ryu, S.; Im, S. MoS 2 Nanosheet Phototransistors with Thickness-Modulated Optical Energy Gap. Nano Lett. 2012, 12 (7), 3695-3700.

(64) Cho, M. Y.; Kim, S. J.; Han, Y. D.; Park, D. H.; Kim, K. H.; Choi, D. H.; Joo, J. Highly Sensitive, Photocontrolled, Organic Thin-Film Transistors Using Soluble StarShaped Conjugated Molecules. Adv. Funct. Mater. 2008, 18 (19), 2905-2912.

(65) Kim, K. H.; Bae, S. Y.; Kim, Y. S.; Hur, J. A.; Hoang, M. H.; Lee, T. W.; Cho, M. J.; Kim, Y.; Kim, M.; Jin, J. Il; Kim, S. J.; Lee, K.; Lee, S. J.; Choi, D. H. Highly Photosensitive J-Aggregated Single-Crystalline Organic Transistors. Adv. Mater. 2011, 23 (27), 3095-3099. 
(66) Lucas, B.; El Amrani, A.; Chakaroun, M.; Ratier, B.; Antony, R.; Moliton, A. Ultraviolet Light Effect on Electrical Properties of a Flexible Organic Thin Film Transistor. Thin Solid Films 2009, 517 (23), 6280-6282.

(67) Xu, H.; Li, J.; Leung, B. H. K.; Poon, C. C. Y.; Ong, B. S.; Zhang, Y.; Zhao, N. A High-Sensitivity near-Infrared Phototransistor Based on an Organic Bulk Heterojunction. Nanoscale 2013, 5 (23), 11850-11855.

(68) Park, S.; Kim, S. J.; Nam, J. H.; Pitner, G.; Lee, T. H.; Ayzner, A. L.; Wang, H.; Fong, S. W.; Vosgueritchian, M.; Park, Y. J.; Brongersma, M. L.; Bao, Z. Significant Enhancement of Infrared Photodetector Sensitivity Using a Semiconducting SingleWalled Carbon nanotube/C60 Phototransistor. Adv. Mater. 2015, 27 (4), 759-765.

(69) Luo, X.; Du, L.; Lv, W.; Sun, L.; Li, Y.; Peng, Y.; Zhao, F.; Zhang, J.; Tang, Y.; Wang, Y. Charge-Transport Interfacial Modification Enhanced Ultraviolet (UV)/nearUV Phototransistor with High Sensitivity and Fast Response Speed. Synth. Met. 2015, $210,230-235$.

(70) Wöbkenberg, P. H.; Labram, J. G.; Swiecicki, J.-M.; Parkhomenko, K.; Sredojevic, D.; Gisselbrecht, J.-P.; de Leeuw, D. M.; Bradley, D. D. C.; Djukic, J.-P.; Anthopoulos, T. D. Ambipolar Organic Transistors and near-Infrared Phototransistors Based on a Solution-Processable Squarilium Dye. J. Mater. Chem. 2010, 20 (18), 3673. 


\section{Table of Contents Image}
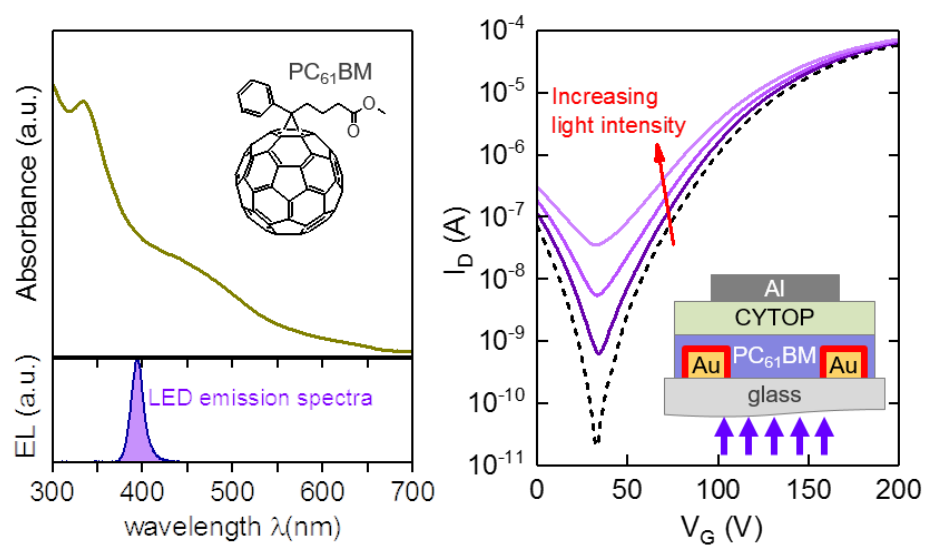